\title{
Evaluationsbogen
}

\section{Nephrotoxische Arzneimittel}

Angaben zur Person

Name, Vorname,Titel:

Straße, Hausnr.:

PLZ/Ort:

Ich bin Mitglied der Ärztekammer (bitte Namen der Kammer eintragen):

Anschrift: $\square$ privat $\square$ dienstlich

Jahr meiner Approbation:

Ich befinde mich in der Weiterbildung zum:

Ich habe eine abgeschlossene Weiterbildung in (bitte Fach eintragen):

Ich bin tätig als: $\square$ Assistenzarzt $\square$ Oberarzt $\square$ Chefarzt $\square$ niedergelassener Arzt $\square$ Sonstiges:

Ich bin DIMV-Abonnent: $\square$ ja $\square$ nein

Falls nein: ich habe den Fragebogen aus/von: $\square$ Thieme-connect $\square$ Kollegen $\square$ der Klinik $\square$ einer Bibliothek $\square$ Sonstiges

L Lernerfolgs-

kontrolle

(Eine Antwort pro

Frage ankreuzen)$$
1
$$$$
\begin{array}{lll}
\hline \mathbf{A} & \mathrm{C} & \mathrm{D} \\
\hline
\end{array}
$$$$
2 \mathrm{~A} \quad \mathrm{~B}, \mathrm{D}, \mathrm{E}
$$$$
3 \mathrm{~A}, \mathrm{~B}, \mathrm{D}, \mathrm{E}
$$

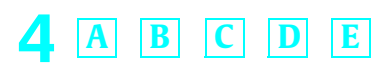$$
5 \mathrm{~A}, \mathrm{~B}, \mathrm{C}, \mathrm{E}
$$

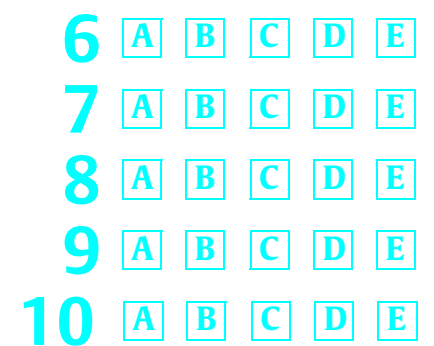

Ich versichere, dass ich die Beantwortung der Fragen selbst und ohne fremde Hilfe durchgeführt habe

Ort/Datum: Unterschrift
Feld für CME-

Wertmarke

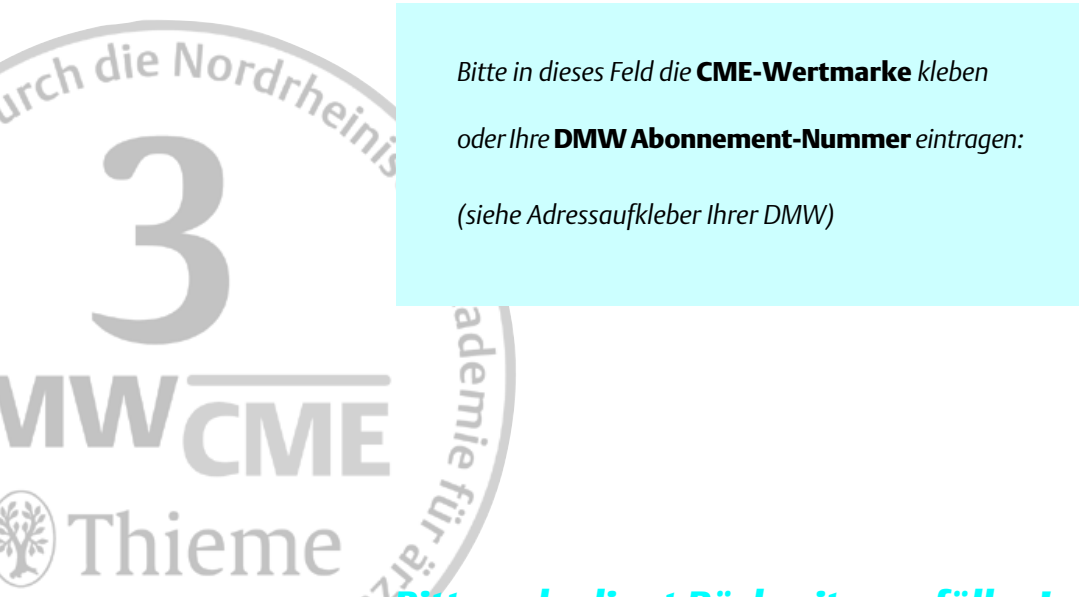

Zertifizierungsfeld (wird durch die DMW ausgefüllt)

\section{Ihr Ergebnis}

Sie haben von 10 Fragen richtig beantwortet.

Siehaben $\square$ bestanden $\square$ nicht bestanden.

$\square$ ungültig, weil:

Stuttgart, den

Datum Stempel/Unterschrift


